\title{
Modern Technology on Automobiles and How to Turn Them into Safeguards of Senior Citizen Drivers: A Review of the Literature and Personal Outlook
}

\author{
Ilias Giannopoulos, IG MSc and Aristomenis Exadaktylos*, AE, MD MSc FRCEM
}

Department of Emergency Medicine, University Hospital and University of Bern, Reiburgstrasse 16c, 3010 Bern, Switzerland

\begin{abstract}
The car is rightly considered one of the greatest inventions of mankind. From its early start it was a sign of technological progress that throughout the years drastically transformed itself but also our way of life. Although the car as an object has been radically revamped through the years, the whole notion of motor transportation remains stable. The car actually means freedom. As Professor Dr. Cotten Seiler points out "Cars have, from the very beginning, represented more than just transportation, cars have historically represented the freedom to go places, to make choices and to pursue many paths. Every driver has the opportunity to be mobile and unrestricted". In addition car means practicality since actually it shortens distance to job, to the super market, to social visits, to the doctor. The car is one of the most important pillars of our social culture. However do new/modern cars offer freedom to every citizen?
\end{abstract}

Keywords: Cars; Technology; Elderly; Driver; Automobile; Senior; Geriatrics

\section{Introduction}

The industry acknowledged the benefits of the car from the very beginning. The history of the automobile begun as early as 1769 , with the creation of the steam engined automobile capable of human transport. In 1806, the first cars using an internal combustion engine which used liquid fuel appeared, and finally in 1886 the German inventor Carl Benz introduced the forerunner of the modern automobile - the Benz Motorwagen (Figure 1). However, during the first few years of the twentieth century, the very idea of the automobile had a fairly limited appeal to the people. Early automobiles were expensive and time consuming to produce, while most cars were too costly for the general public. However, Colorado State University reports that "Between 1904 and 1908, 241 different firms began producing cars aimed at the American consumer. In 1908, Ford Motor Company created the Model $\mathrm{T}$, the first car aggressively marketed to the average family. By widening the sales base for the automobile, Ford did a great deal to create an industry for cars and car products" [1,2].

In the 1920's it was a time of great growth for the auto industry, as more and more consumers bought their first car. The Chrysler Corporation was started in 1925, and many other small car companies began during this decade. By 1929, the year of the stock market crash that began the Great Depression, car companies were producing and selling 5.3 million vehicles a year. World War II helped the American economy emerge from the Great Depression, and prompted growth in the auto industry, and during the 1950's and the 1960's two radical changes happened. In the 1950's the car became an integral part of the American dream, thus it started to acquire a strong social identity as an object while in the 1960's the auto industry focused on making safer vehicles that could meet the needs of the modern consumer according to Bryant University [3]. In 1964, Studebaker-Packard was the first company to introduce seat belts as standard equipment on all of its vehicles. In addition to safety, car buyers of this era expected vehicles to be powerful and spacious, and fuel economy was not a major concern.

However, this changed in the 1970's. The OPEC oil crisis forced automakers to think on how to create vehicles that were more fuelefficient. The next step took place in the 1980's with the growth of the globalized auto industry. The high demand for vehicles, combined with the low cost of skilled workers in countries like China, led to a situation where manufacturers in those countries could produce cars at a fraction of the cost of U.S. and European manufacturers. Automakers could then export those less expensive vehicles to developed countries across the world. According to a 2009 Duke University report [4] on the auto industry, in 1975,80 percent of global auto production came out of seven countries. By 2005, 80 percent of global production came from 11 countries, representing a widening of the playing field and a significant growth in global competition. Last but not least the factor that also transformed the car is technology. The average family saloon car of today has nothing in common with the one from the 1990's. More or less the low cost of production of technological gizmos that were once the prerogative of expensive cars proliferated down the range on the offerings of almost every car manufacturer. Nowadays, Bluetooth, GPS navigation, assist parking sensors, and all sorts of useful or sometimes not so useful electronic systems are standard equipment (Figure 2).

So, the automobile started its life as an expensive toy and then though the ages influenced by social and technological changes became actually a pillar of social cohesion, an integral part of our way of life. In the present the car is safer than before, more fuel efficient, better assembled, designed with many safety features for its passengers and pedestrians alike, and also designed to appeal to a more global audience. However, here lies a problem. The overwhelming majority of automotive industries design and equip their cars in order to appeal to active and younger clients that are fixated with technology. Joseph Coughlin, director of the Age Lab at the Massachusetts Institute of Technology states that "It's hard to avoid too much technology. New vehicles feature an ever-growing array of gizmos, a lot of which are standard. "The velocity of technological change is only going to continue and will accelerate" [5].

*Corresponding author: Dr Aristomenis Exadaktylos, Professor of Emergency Medicine, Chair and Clinical Director Department of Emergency Medicine, University Hospital Bern, Inselspital 3010 Bern, Switzerland, Tel: +413163224 42; E-mail: Aristomenis.Exadaktylos@insel.ch

Received: April 06, 2017; Accepted: May 02, 2017; Published: May 11, 2017

Citation: Giannopoulos I, Exadaktylos A (2017) Modern Technology on Automobiles and How to Turn Them into Safeguards of Senior Citizen Drivers: A Review of the Literature and Personal Outlook. Int J Adv Technol 8: 185 doi:10.4172/0976-4860.1000185

Copyright: (c) 2017 Giannopoulos I, et al. This is an open-access article distributed under the terms of the Creative Commons Attribution License, which permits unrestricted use, distribution, and reproduction in any medium, provided the original author and source are credited. 


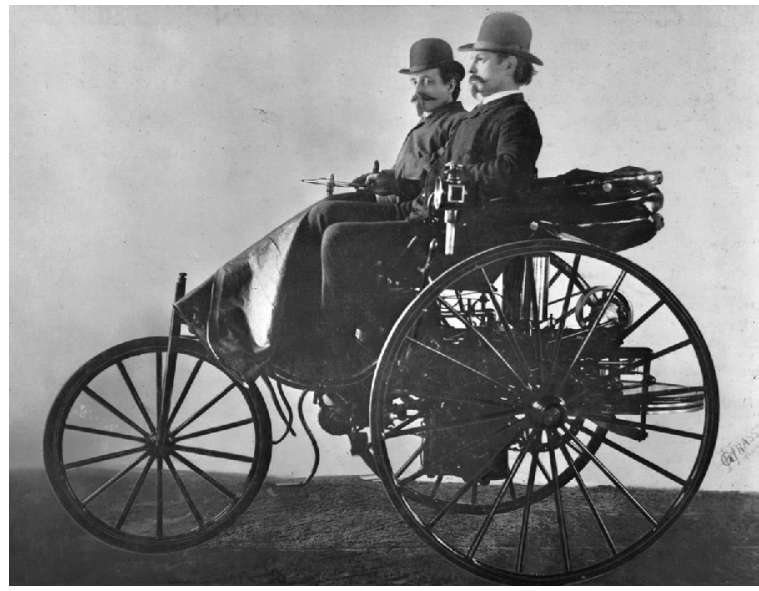

Figure 1: Benz patent motor car, 1886 - the world`s first automobile.

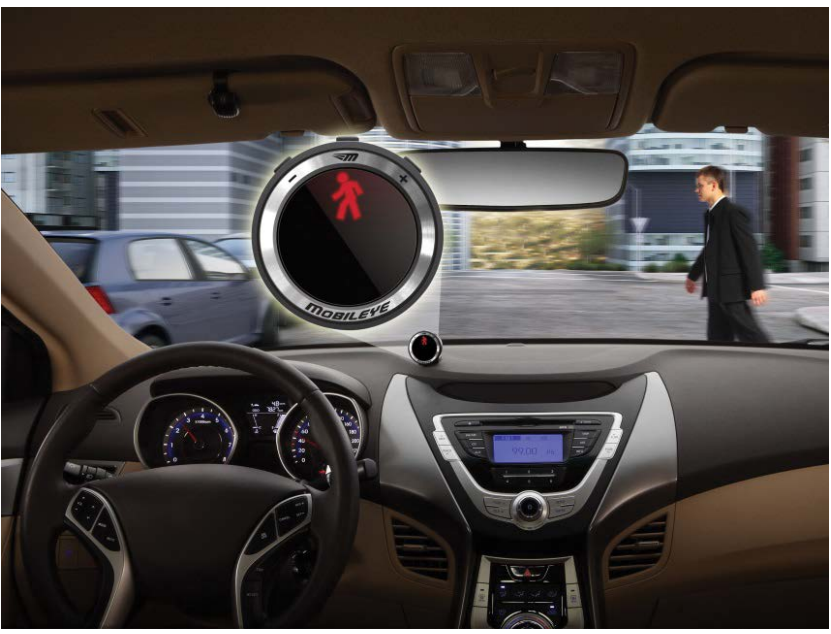

Figure 2: Self-driving car.

\section{Technological overload}

New technologies are being introduced into the car that alters the way the driver controls the vehicle [6]. Typical examples are adaptive cruise control, which allows a driver to maintain a constant speed, but also a constant distance from vehicles traveling in the same lane (Figure 3 ). Thus speed is no longer solely controlled by changing the pressure on the accelerator or brake pedal. The car automatically accelerates and decelerates within preset limits. Various types of warnings are now installed in cars, including forward-collision warnings, backup warnings, and lane-departure warnings. Night-vision systems and various cameras provide drivers with visual information. These and other enhanced vision systems are becoming additional sources of information for controlling the vehicle.

Cars are also are equipped with sophisticated GPS systems. These include navigation systems that help a driver find a route toward a destination by providing turn-by-turn directions or by showing the route on a map display. They may also provide traffic advice, informing a driver about congestion, accidents, or road work, and can help a driver choose a route with minimal delays. Additionally, these have a dual purpose of providing a much more comforting environment for the passengers because they provide not only entertainment, but

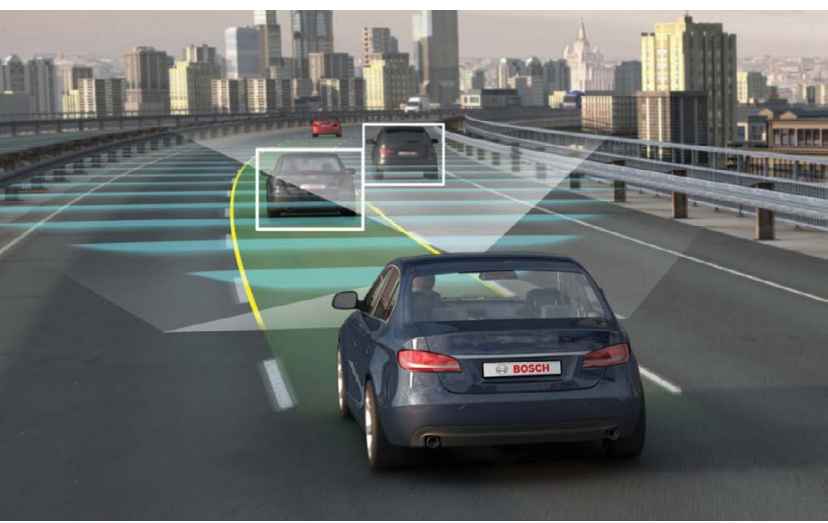

Figure 3: Distance and speed control.

also access to information. In addition, they can communicate with people outside the car and to interact with all three types of devices. For instance, a computer display may show the view from a rearfacing camera when the car moves backward. The same computer may also show route information for navigation and provide access to the entertainment system or a screen for reading text messages. Although these devices can have great benefits for a driver, they can also interfere with safe driving. And at this point the problem starts from information overload (Figure 4).

Demographics are changing. Known as the "silver tsunami" a vast percentage of the population of is about to enter its geriatric years. "The 70-plus crowds are projected to increase from 30.1 million in 2013 to 53.7 million by 2030 in the U.S.A alone. There will be more aging drivers on U.S. roads in the coming years, continuing a trend that's been building for more than a decade. The Insurance Institute for Highway Safety (IIHS) estimated that the number of licensed drivers 70 years old and older jumped 30 percent between 1997 and 2012. Older drivers have also been traveling more miles. From 1996-2008, average yearly mileage for drivers 70 and older rose by 42 percent" [7]. In addition the economic crisis means that these aging baby boomers might be in a better position to actually buy a better car than the $30+$ generations. Hi-tech innovations are often introduced into high-end and expensive cars, which are commonly bought by wealthier (and usually older) costumers. As a result, people in this aging demographic are often the first to encounter cutting edge technology. On top of that, because of the modern way of thinking, people in this demographic segment are much more active than they used to be.

In many countries like in Switzerland for instance or in Greece driving a car is not bound to an age limit. Therefore, companies actually build cars fully loaded with electronic gizmos that sometimes frighten senior citizens due to their complexity. In addition these gizmos are not oriented towards this demographic segment. Seniors face many more issues in order to be classified as safe drivers. As Olson and Sivak point out "Among them are age-related changes in night vision, contrast sensitivity, recovery from glare, and a decrease in the useful field of view (i.e., the width of the visual field over which information can be acquired in a quick glance). Aging is also accompanied by general slowing in processing speed. The initiation of responses and their execution become slower, especially for unexpected events" [8].

In addition new technology and the overload of information can create other issues. The first is that all these information can distract the senior driver. "With age, the ability to focus and divide attention tends to decrease. In-vehicle devices often require that a driver divide attention 


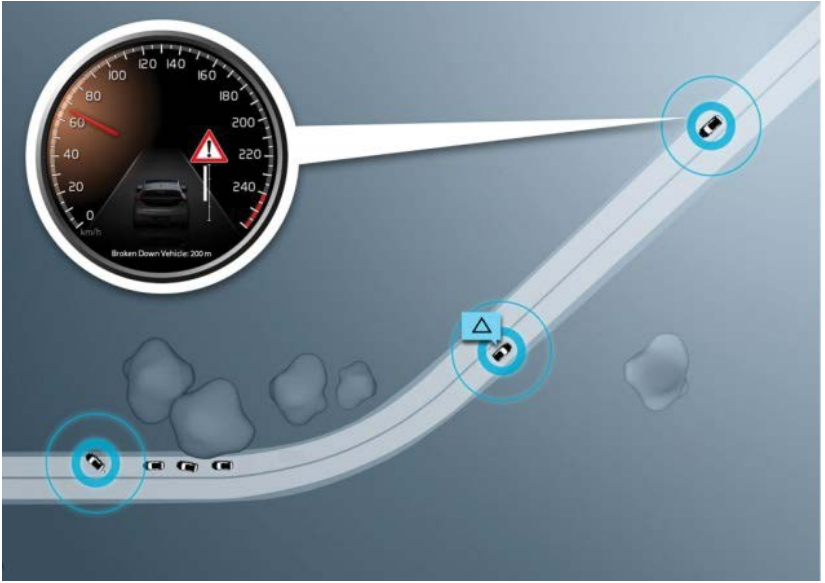

Figure 4: Car-2-Car and Car-2-Object communications technology.

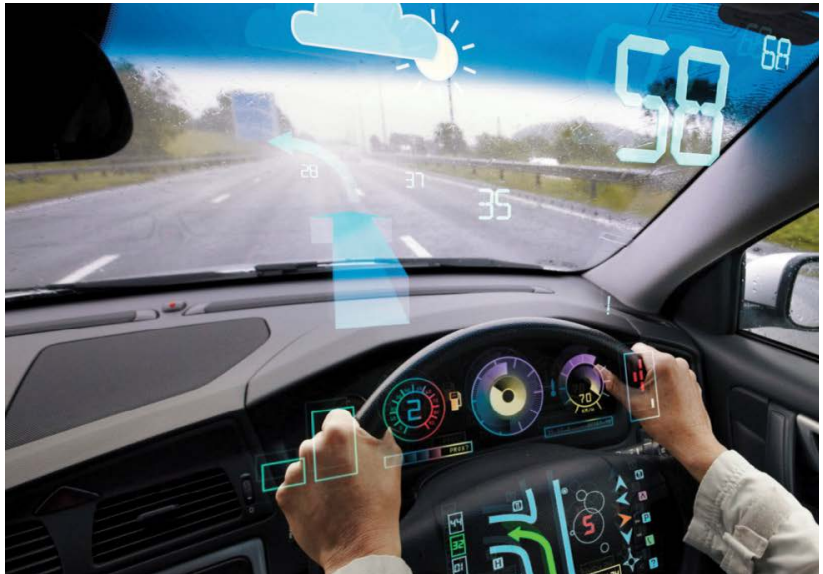

Figure 5: Driving in the future. between driving and using the device" [9]. Many senior drivers have even problems using their car radios. In addition, there is a problem called 'automation bias,' which is created from the limiting perception of old drivers to learn how to use a new system. As Parasuraman and Riley stress "If a driver comes to rely entirely on the new system, for example, a lane-departure warning, or an intelligent cruise control system that maintains spacing between cars, he or she may eventually begin to initiate a lane-change maneuver without bothering to look, assuming that the warning system will issue a cue if the lane is occupied. However, these systems are considered convenience systems and are not designed to be safety system" [10]. Therefore, these systems and their implementation are not sufficiently reliable for someone who cannot fully understand their limitations and their benefits.

\section{Technology and the challenges ahead}

New technology however can actually help senior drivers and the key is knowledge and education (Figure 5). The first step is to actually explain how this can be done. In order this to become a reality we must first reach a point where companies and organizations find ways to explain actively (through experienced personnel) or passively (by offering simpler car system manuals) to seniors how technology can actually help them and also how they can integrate all these info on their driving routine. Here, we must notice that older drivers have a great ace up their sleeve, which lies in their experience behind the wheel, and that in general makes them very safe drivers $[9,10]$.

The equation becomes more difficult however, when we add the technology factor. As Craik and jacoby point out the need to learn new skills, related to new devices, may render their previous experience obsolete. Although people are often able to perform familiar tasks and skills up to a very advanced age, learning new skills and changing familiar routines becomes more difficult with age" [11]. Even apparently simple systems, such as rear-view cameras, require learning new skills.

Car manufacturers are keenly aware of this and they are making attempts to rectify the issue. General Motors, for example, recruits individuals 60 and older to test its infotainment systems. Ford Motor uses a so-called "Third Age" suit to help engineers and designers understand how physical limitations can affect driving....The Collaborative Safety Research Center at the Toyota Technical Center in Ann Arbor, meanwhile, has a variety of projects related to older drivers, partnering with universities and other institutions. In the USA, AARP (American association for retired Persons) provides a Driving Resource Center that features an interactive demonstration of the top
10 technologies for mature drivers, while AAA's (American Automobile Association) Senior Driving Web site has a Smart Features for Older Drivers tool that lets seniors input their specific needs to find a car that works best for them [12].

The next step would be for companies to actually develop systems that are much simpler to use. Well designed and above all intuitive technology can actually be beneficial towards most of the problems that are enhanced by age-related changes. Active safety systems which use cameras and sensors to alert drivers of looming danger will sharpen the reactions of older drivers; 360-degree camera systems can help in parking or more importantly can enhance the perception behind the wheel. Additionally, adaptive headlights, which swivel in the direction the steering wheel is turned can also help people with impaired visual ability. Furthermore, automatic crash notifications; automatic high beams; blind-spot warning; drowsy-driver alert systems; keyless entry; adjustable steering wheels and pedals; power seats; and motorized trunk lids can on a large extent offer a much more pleasant driving experience for their users $[11,12]$.

For instance, as Herriotts states "a major problem for many older people is decreased flexibility. In a survey of older drivers in the United Kingdom, more than half of the respondents mentioned difficulties with turning their heads and looking out the rear windows. The reduced motility of the neck and head, combined with a narrower useful field of view, may increase the likelihood that an older driver will collide with an object behind the car when backing up. When changing lanes, older drivers may also be less likely to see a vehicle coming from behind in a parallel lane" [13].

Alerts and various visual aids, such as rear-view camera systems and Head Up displays, can help mitigate these issues. But in order older drivers to benefit from them, their designers must consider the users' abilities and characteristics that require a different design and presentation towards the driver. For example, interfaces should be as simple and intelligible as possible. "Almost everyone over the age of 60 has trouble focusing sharply on nearby objects, a condition called presbyopia, and most people require corrective lenses to view close objects" [14]. While driving, drivers will not put on reading glasses to use a system, and they may find driving with bi- or multifocal glasses unpleasant. Therefore, in-vehicle displays and devices should be designed so that drivers with presbyopia can still use them.

The design of intelligent interfaces that predict and warn for every 
possible action by the driver can also help assuage age-related problems. "Adaptive software may make these devices safe and acceptable for older drivers. For instance, auto supplier Visteon is working on systems that read the driver's eye movements and hand motions. "Everyone wants a vehicle that's more intuitive and easier to use," said Richard Vaughan, director of corporate innovation and design at Visteon. "The technologies we're working on will benefit everybody. In addition to the aging, there are 47 million people in the Untied States with some degree of disability" $[15,16]$.

\section{Conclusion}

The very idea of the car and the whole notion of driving are changing more rapidly today than at almost any other time in the last century. However, still the basic idea of driving a car remains the same. The accelerator pedal and the brake pedal are inputs that regulate the speed, while turning the steering wheel controls the relative axis of direction for the vehicle. What actually changed is the technology that makes the car safer and easier to use. The car nowadays is a proof of our way of life, of the current social condition prevailing in the industrialized society. As such is full of technology that promises ease of use. However, this technological overload has its downsides especially for senior citizens since they cannot most of the times attach to their driving routine every input they receive from these aides, despite the fact that these can actually make their life easier behind the wheel alleviating possible health problems.

So technology is available but most of the times instead of a tool to help, creates a burden. Technology should be designed in such a way that can be beneficial for people from all demographic segments. Companies must educate actively or passively, and also must design new or re-design current systems so that senior citizens can actually use them with safety, and, more important, so that new devices make life more comfortable. Older people do not need cutting edge technological marvels but systems that are intuitive because a badly designed system will affect negatively the people in this demographic in the most profound way. Therefore a system that incorporates a design that takes into account of older driver's characteristics and needs is cornerstone.

Although extensive research has been made by institutions and the automotive industry, there are still large areas in our effort to learn how to design intuitive in-vehicle devices, that can be used by potential customers from every demographic segment. The research and various developing models of technology implementation, especially by senior citizens, constitute a major challenge. As J. Mayer states in his article 'Technologies for an aging population, designing in-vehicle technologies for older drivers, meeting that challenge will require the collaboration of engineers, psychologists, physicians, and practitioners in many other disciplines. The insights gained from such efforts will have implications for almost all domains of life, not just vehicle design. Technologies designed with an eye to older users will not only provide an important service for older drivers and society as a whole by increasing mobility and making driving safer, but are also likely to be a major business opportunity for automobile manufactures" [1]. Knowledge, education and design of intuitive technology in cars are factors that can create a win-win situation for everyone.

Citation: Giannopoulos I, Exadaktylos A (2017) Modern Technology on Automobiles and How to Turn Them into Safeguards of Senior Citizen Drivers: A Review of the Literature and Personal Outlook. Int J Adv Technol 8: 185. doi:10.4172/0976-4860.1000185

\section{References}

1. Seiler C (2008) Republic of drivers: A cultural history of automobility in America. University Of Chicago Press.

2. http:///3d.cs.colorado.edu/systems/agentsheets/New-Vista/automobile/

3. http://web.bryant.edu/ ehu/h364/materials/cars/cars\%20_90.htm

4. Sturgeon TJ, Memedovic O, Van Biesebroeck J, Gereffi G (2009) Globalization of the automative industry, main features and trends. Int $\mathrm{J}$ Technological Learning Innovation and Development 2: 7-24.

5. Chapman M (2016) Senior drivers confront proliferation of new car technology, Chicago Tribune.

6. Ashley S (2008) Driving towards crashless cars. Scientific American 299: 8694.

7. http://www.horsepoweronline.com/2015/12/car-technology-that-improvesolder-\%20drivers-safety/

8. Olson PL, Sivak M (1986) Perception-response time to unexpected roadway hazards. Human Factors 28: 91-96.

9. Greenwood PM, Parasuraman R, Alexander GE (1997) Controlling the focus of spatial attention during visual search: Effects of advanced aging and Alzheimer disease. Neuropsychology 11: 3-12.

10. Parasuraman R, Riley VA (1997) Humans and automation: use, misuse, disuse abuse. Human Factors 39: 230-253.

11. Craik FIM, Jacoby LL (1996) Aging and memory: implications for skilled performance. Aging and skilled performance: advances in theory and applications.

12. Chapman M (2016) Senior drivers confront proliferation of new car technology. Chicago Tribune.

13. Herriotts $P(2005)$ Identification of vehicle design requirements for older drivers. Applied Ergonomics 36: 255-262.

14. Weale RA (2003) Epidemiology of refractive errors and presbyopia. Surv Ophthalmol 48: 515-543.

15. Phelan M (2014) New technology makes driving safer for seniors. Detroit Free Press.

16. Mayer J (2009) Technologies for an aging population, designing in-vehicle technologies for older drivers. The Bridge.

\section{OMICS International: Open Access Publication Benefits \&}

\section{Features}

\section{Unique features:}

- Increased global visibility of articles through worldwide distribution and indexing

Showcasing recent research output in a timely and updated manner

Special issues on the current trends of scientific research

Special features:

- $700+$ Open Access Journals

$50,000+$ Editorial team

Rapid review process

Quality and quick editorial, review and publication processing

Indexing at major indexing services

- Sharing Option: Social Networking Enabled

Authors, Reviewers and Editors rewarded with online Scientific Credits

- Better discount for your subsequent articles

Submit your manuscript at: www.omicsonline.org/submission/ 